\title{
Environmental issues resulting from scientific and technical progress
}

\author{
Olena Sidorkina ${ }^{1, *}$, Oksana Skyba $^{1}$, Nadiya Sukhova ${ }^{1}$, Tetiana Poda $^{1}$ \\ ${ }^{1}$ National Aviation University, Kosmonavta Komarova ave., 1, Kyiv, Ukraine
}

\begin{abstract}
The article explores the environmental issues of mankind being a negative consequence of unrestrained scientific and technological progress. Environmental issues have become global because they have reached a level that threatens the possibility of life on Earth. More and more scientists are becoming aware of the need to find new moral and ethical regulations that can change the consumer attitude to nature, help them to realize their responsibility towards it. It suggests the idea of the emergence and formation of a new ethics - the ethics of responsibility. That is, modern moral and ethical principles should not only allow humanity to enjoy all the benefits of scientific and technological civilization, but also to warn against the foreseeable possible threats.
\end{abstract}

\section{Introduction}

The environmental issues of mankind, which arose in the last century, at the beginning of the new XXI century, reached such a level that they threatened the possibility of further existence of life on Earth and human survival. Under such circumstances, the need to search for such new moral and ethical orientations, in which life itself and its preservation will be of paramount value, has not only lost its relevance, but also acquired a new meaning. More and more scientists are coming to believe that modern moral and ethical principles should not only allow humanity to enjoy all the benefits of scientific and technological civilization, but also to warn against the foreseeable possible threats. The world of high technology, as some scholars rightly point out, remains a neutral territory for ethical theory. And in this vacuum, the only thing that can serve as a compass is the most anticipated threat. In the likelihood of its planetary scale and its consequences for humans, ethical principles must first be discovered, on the basis of which new responsibilities can be deduced from the new power of man. This is the "heuristics of fear": only the alleged distortion of a person helps to understand a man who must be preserved ... This newlyinterpreted duty may be comprehended as the concept of responsibility, as mentioned in the previous work (Skyba, 2014: 71).

Today's ethics of responsibility embraces several types of interpretation of the responsibility concept. In the technocratic sense of responsibility, the idea of foresight, planning for the future is most important. Responsibility is therefore a guarantee of the process of reality transformation, technological development and knowledge growth. The

* Corresponding author: sidorkina.a@gmail.com 
ethics of the responsibility of technocratism is aimed at securing, through controlling mechanisms, from unforeseen circumstances (for example, from certain environmental disasters). Therefore, it demands certain obligations to the human community, acting as an authoritarian conscience and a mechanism for generalizing political or economic influence on the mass consciousness. As for the humanistic reading of responsibility, the emphasis is shifting to the sphere of interpersonal relations and relationships in the "man-world" system. In this case, to be responsible means to be attentive to both one's own actions and natural tendencies, their mutual agreement. Responsibility is a wise and careful handling of the environment, delicacy and caution in actions, taking into account all possible side effects of the activity and, finally, recognizing one's natural being. If the technocratic justification of responsibility is monologic and characterizes the subject-object relation to the world, then the humanistic is oriented towards establishing authentic, dialogical interaction with the surrounding reality (Vysotska, 2012).

In the modern world, anthropocentric perceptions of the relationship between man and nature have become increasingly negative as of late, in which man regarded nature as merely a means of achieving goals. A number of scientists, namely: A. Leopold (Land Ethics), A. Schweitzer (The Ethic of Reverence for Life), V. Potter (Global Bioethics) in their ethical and philosophical concepts make a ruthless sentence to a consumer society and draw attention to the need to change spiritual orientations. G. Jonas, K. Maier-Abih, and others also advocate the solution of the problem of the human-nature relationship based on morally ethical principles and the principle of responsibility. Various approaches to reading the concept of responsibility are demonstrated in the works by I. Kant, which links responsibility with the "freedom" of human actions; E. Fromm points out the anthropological nature of a sense of responsibility, turning to the ideals of Christian love, which is a responsibility to others, "not imposed from the outside" (Fromm, 2006).

Among the national scientists S. Krymskiy ought to be remarked, who notes the sociocultural conditionality of scientific knowledge in his works, draws attention to the danger of the existence of "extra-ethical" knowledge, which became the alarming reality of the modern era of scientific and technological revolution (Krymskiy). It is worth paying attention to the work of S. Pustovit, who examines the basic conceptual models of bioethics, paying particular attention to the issues of medical and environmental bioethics as components of global bioethics. W. Potter stated: "The existence of the world must not depend on the ability of Nature to tolerate our images and endlessly sustain the lives of our descendants. Science cannot replace the generosity of Nature when the latter is devastated and plundered" (Nasibulina, 2014).

\section{Purpose and tasks}

Throughout the existence of mankind, the attitude to scientific knowledge and technical inventions has been constantly changing. There was a time when scholarly treatises and manuscripts were burned at the Inquisition bonfires (sometimes authors inclusive, one has only to mention Giordano Bruno), since the Christian Church had long believed that no other knowledge was needed after the Bible. The inventors of new technical mechanisms have also often been persecuted and repressed; the known historical fact in the 16th century is that the mechanic who created the loom for braidings was executed. The reason for the massacre was the fear of the authorities that the use of this invention would cause unemployment. Another attitude towards science and technical inventions was formed in the era of modern times, when the traditional society was being replaced by the industrial society, and science began to act as a panacea that would solve all the problems of humanity. 
As of today, the desire for knowledge of the world or for the maximum comfort that modern equipment can provide to a person has not lost its relevance. After all, many of us do not imagine work, study and even everyday life without mobile phones, the Internet, microwave ovens, refrigerators, etc. However, recognizing the fact that scientific and technological progress has also undesirable negative consequences, among which environmental issues are not in the last place, leads scientists to the need to find new moral and ethical regulations that can change the consumer attitude to nature, to realize their responsibility towards it. This leads to the idea of the emergence and formation of a new ethics - the ethics of responsibility, which will become the basis not only for the formation of environmental ethics, but also a space for the development of new ethical and environmental paradigms for solving environmental issues in different fields.

\section{Research methodology}

The theoretical and methodological basis of this study are the general scientific and special methods and approaches, with the help of which the consequences of the ways chosen by mankind of the scientific, technical and economic development of humanity and the possibility of preserving the global natural environment will be investigated. One of them is a systematic approach. Its use will make it possible to study environmental issues both globally and in individual regions, will provide a comprehensive and multi-faceted study of the natural environment using the full range of methods. The systematic approach allows to reveal the integrity of ecosystems at different levels of the hierarchy, to trace and predict the dynamics of changes in the ecosystem under the influence of anthropogenic activity, as well as to solve the problems of human survival as a species. The synergistic approach to the study of the ecosystem is also justified, as it is characterized by openness to dialogue and the possibility of self-organization.

\section{Findings}

The science requires, as viewed by S. Krymskiy, “... social control, which has directed it to serve social progress. Beyond socio-moral use, scientific knowledge loses its cultural and humanistic dimension; cynicism devoid of moral horizons of knowledge gives rise to Faustian collisions ..." (Krymskiy, 2009:34). The consequence of such a science culture is that the achievements of science and technology are not always a boon to humanity and can turn to the means of global destruction, if the progress of moral consciousness does not take place.

The Club of Rome is one of the first non-governmental international organizations, which focused its attention on such issues: can the environment be preserved at regional and global levels as well as economic equilibrium, the sustainability of social development and comprehensive natural resources, if the use and consumption of energy and raw materials in industrialized countries will continue to take the easiest way, guided only by narrow economic interests? Well-known reports at the time drew the attention of ordinary people and leaders to the "difficulties of mankind", which A. Peccei, the first president of the Club of Rome, called global socio-economic and environmental issues, the reason being that "no one bears or even feels responsible for the state of the whole world... No one cares about the world and, accordingly, no one wants to do for it more than others... There was no group in the world that dealt with contemporary issues in their entirety. A single, global approach that requires not only identifying individual parties to an issue, but also their impact on one another and on the whole system as a whole, has in fact never been used by anyone..." (Mokiy, 2015). 
International environmental NGOs include the International Union for the Conservation of Nature and Natural Resources (IUCN). A significant event was the 14th IUCN General Assembly, held on 26 October 1978 in Ashgabat, which adopted calls for the suspension of further development and use of nuclear, biological, chemical and other environmental polluting weapons; the basic requirements for nature protection have been formed, the natural ecological systems of the planet, which are experiencing a particularly heavy load on the part of human economic activity, have been identified. The United Nations (UN) is also addressing environmental issues for future generations, such as making chemical safety decisions.

Over the last decades, there has been a trend in many international environmental issues. For example, the European Council of the European Union has adopted a new standard (BS 7750) for a wide range of industrial and agricultural products and businesses, which more strictly regulates environmental pollution, energy costs for production, noise pollution and more. Products that adhere to this standard receive the Green Dove sign, which gives certain advantages in the commodity market.

At the same time, despite the measures taken, some environmental issues still remain acute, in particular the problem of plastic pollution of the oceans. Even if the pollution of the ocean by sewage, fuel and other debris is not taken into account, the annual consumption of plastic bottles exceeds the activity of processing them and threatens the oceans, coastlines, the environment. One million plastic bottles are purchased every minute, and new data from the Guardian show that plastic bottles usage is increasing. In 2016, around 480 billion plastic bottles were sold worldwide, as compared to 300 billion ten years ago. If put together, they will extend more than half the way to the Sun. By 2021, this number will increase to 583.3 billion per hour, according to the latest estimates from the global export report Euromonitor International (The Idealist). A certain percentage of bottles are being recycled, however, as demand for their use in the world is increasing, there is too little processing effort. Today, companies are increasingly using biodegradable plastic, based on starch, cellulose, etc.

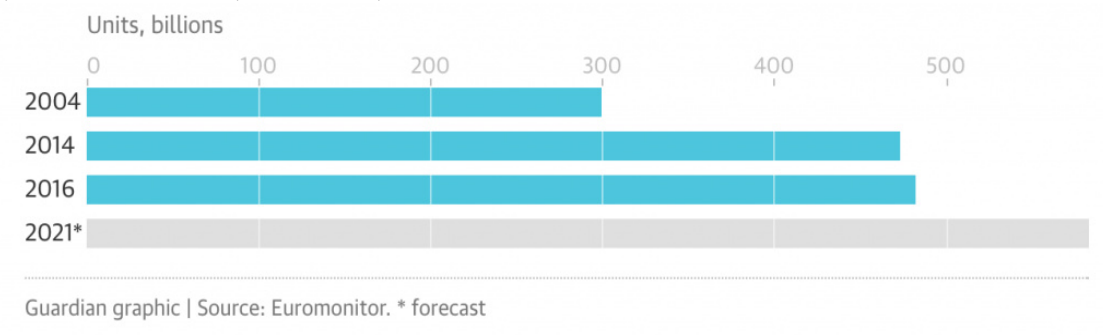

Fig. 1.

Microplastics (small pieces of plastic sized from nanometer to rice grain) also cause great damage to health. They cannot be filtered out, and they have the capacity to accumulate in the body, which causes great harm. These particles are found in water, air, in many cosmetics (lipstick, creams, peels, etc.).

Table 1. Sources of microplastics in the World Ocean (source: IUCN, Orb. Media).

\begin{tabular}{|c|c|c|c|c|c|c|}
\hline $\begin{array}{c}\text { Synthetic } \\
\text { fabrics }\end{array}$ & Car tires & City dust & $\begin{array}{c}\text { Road } \\
\text { marking }\end{array}$ & Ship paint & $\begin{array}{c}\text { Hygiene } \\
\text { products }\end{array}$ & $\begin{array}{c}\text { Plastic } \\
\text { granules }\end{array}$ \\
\hline $35 \%$ & $26 \%$ & $24 \%$ & $7 \%$ & $3.7 \%$ & $2 \%$ & 0,3 \\
\hline
\end{tabular}

Therefore, it is an urgent opinion that in an age of high technology, moral guidelines and ethical principles should serve as life guidelines for humans. After all, if in the last century, when plastic was just beginning to spread, people thought not only about profit, but also what to do with a huge pile of plastic in a hundred years, the situation seemed more 
optimistic. As for the notion of responsibility in the new ethics for high-tech civilization, the modern philosopher K. Mayer-Abich rightly notes that “... there must be not only responsibility for other people, not only responsibility for animals and plants, but also responsibility for all things created by man and not created by him, because "not man is the measure of all things, but everything that surrounds us, is the measure of our humanity" (Mayer-Abich, 2004: 96).

\section{Discussion}

Like any other activity, scientific knowledge has certain ideals and norms, methodological and value regulations that organize and guide the process of scientific knowledge at a particular historical stage in its development. As a kind of spiritual activity and social institute, science emerges in the era of modern times. Scientific knowledge is of the highest value among the spiritual landmarks of this era. A well-known slogan proclaimed by modern-day rationalists "Knowledge is power" gave rise to a desire to subjugate nature and to create an ideal society on the basis of Reason. It is known that rationalism manifests itself to a certain extent in the Antiquity, but in the ancient culture, the pursuit of truth, wisdom without benefit calculation, was a priority, there was no connection with practice, experiment, and in theory itself primarily valued not the benefits, but beauty.

The ancient world for the first time creates a theoretical system of scientific knowledge when science does not exist in the proper sense of the word (as we use it today). Only theoretical forms of thinking, methods, logical and epistemological foundations and principles of cognition are born, on the basis of which science is born as a systematic collection of theoretical provisions and practical methods for the study of the subject. The boundaries and nature of the created system of knowledge are determined by those methods of posing questions to nature, which the ancient Greeks possessed. A fundamentally new moment is the emergence of a theoretical tradition that distinguished ancient science from the development of ancient knowledge in general. It organized all the accumulated empirical material, gave a philosophical explanation of the world and its properties (materiality, motion, space, time); it introduced mathematical research methods (designed to meet the needs of astronomy); the Greek geometry is developed, built on the basis of axiomatics. Another tradition of ancient science - practical, handicraft -is the tradition of "technical mechanics", architects and engineers, designed to give specific rules for the behavior of designed simple machines (lever, block, wedge, screw). It should consider the activities of Archimedes, Hieron, Vitruvius, et al. Considering that the practical activity of that era was still underdeveloped and did not form the basis of cognition in the form of experimentally measurable procedures, then other characteristics were transformed into natural philosophy and speculativeness (Skyba, 2014:72). That is, the negative attitude of the ancient Greeks to the theoretical knowledge that is applied in practice must be remembered. To some extent, the very reluctance of "lovers of wisdom" to relate to "secondary" knowledge contributed to the development of theoretical tradition and philosophy.

The Renaissance is characterized by a more severe pursuit of scholars by the Inquisition. However, it should not be forgotten that at this time there are great scientific discoveries, there are Natural science (non-theological) departments in the universities, there is a formation of a new outlook and science, in no small measure associated with the names of G. Galilei, J. Bruno, M. Copernicus and others. This is the transition from the Middle Ages to the Modern Age, where cognitive activity comes first, as well as the "principles" and "fundamentals" hidden in some of the "innate" faculty of reason (R. Descartes) or in the determination of the individual's thinking through development of his experience (F. Bacon). At this time, science is emerging in its modern sense, certain 
methods of scientific knowledge are being developed, stereotypes of science are being elaborated, which rationalism sees in the mind, sensualism-in the senses, empiricism - in the experience.

The majority of prominent scientists of the XVII-XVIII centuries (including F. Bacon), no longer think of the development of scientific knowledge beyond its practical results, thus forming a consumerist attitude to scientific knowledge, contrary to the contemplation of truth in the antiquity. There is a reorientation of science in the light of the proclaimed idea "Knowledge is power." Such a sharp rethinking of the ideals of scientific knowledge led to the fact that science began to be regarded as both a goal in itself and as a universal means: cognition, subjugation of nature, perfection of man, improvement of civil affairs had to inevitably give birth to an industrial civilization with its science and technology consciousness.

The renowned physicist Louis de Broglie rightly observed "great discoveries, even made by researchers who did not pursue any practical application and were engaged solely in the theoretical solution of problems, quickly found application in the technical field. Of course, M. Planck, when he first wrote the formula that bears his name, did not think of lighting technology at all. But he had no doubt that his considerable efforts of thought would allow us to understand and anticipate the considerable number of phenomena that would be used rapidly and in increasing numbers by the lighting technology. Something similar happened to me. I was very surprised to see that my ideas quickly find specific applications in electron diffraction and electron microscopy" (Skyba, 2014:72). Indeed, scientists do not always see all the fields of application of their discovery that, in addition to the apparent benefit, can hide threats.

Knowledge applied in practice produces consequences that impose responsibility on the authors. Meanwhile, the gap between the fundamental knowledge and the applied results leads to a situation where foresight is a matter for some individuals, while the responsibility lies with others. Science is confidently proclaimed as the highest value and it holds a leading place in the culture of the era, therefore it gives the world to the uncontrolled power of technology, creating the conditions for the development of a civilization that adores technology. However, it should be noted that if for most people the danger of such an approach became apparent only at the end of the XX century, then within the philosophy of life, this was noticed much earlier. Scientists began to realize the need to change attitudes to nature, and their responsibility for the possible consequences of their discoveries, avoiding those areas of work that can bring disaster.

\section{Conclusions}

Technological civilization gives man great power that cannot be accepted without a sense of responsibility for life on Earth. This leads to the idea of the emergence and formation of a new ethics- the ethics of responsibility. Modern technology and consumer attitude towards nature, which at one time aimed at the happiness of people, has become a threat to the existence of humanity as such. Techne, as a human aspiration that was once a necessity, a means, in its progress, transformed humanity and the imperative to respond to a new type of human activity, may sound as follows: "Do so that the consequences of your activity are not devastating ... we may risk our own lives, but we have no right to risk the lives of mankind" (Iakovenko, 104). And the fact that the existing ethics, limited to the sphere of purely human relations, does not correspond to the "new modalities of human power" indicates the need to form such spiritual guidelines that will ensure the survival of mankind and new unknown dimensions of responsibility. One such guideline is the idea of extending moral and ethical principles towards nature. For man is truly moral only when he obeys the inner desire to defend any life and refrains from harming the living being. 
Of course, the ideal life of the noosphere on the planet according to the laws of ecology is impossible, but the more mankind can approach the ideal of harmonious relations of man with nature, the greater the probability of its survival. A comprehensive analysis of the components of ecosystems, knowledge of the laws and fundamental laws of ecology makes it possible to predict the effects of anthropogenic impact on the biosphere and to prevent the negative effects on ecosystems. Theories of "organic" growth, sustainable development, coevolution, noospheric ethics are different interpretations of the approach to solving environmental problems by changing the environment itself.

\section{References}

1. O.E. Vysotska, Ethics of Interaction of Society with Nature: Moral and Value Foundations of Ecological Culture. RoyalPrynt, Dnipropetrovsk (2012)

2. A.M. Yermolenko, Ecoetics in the Light of Paradigm Turn in Philosophy (preliminary notes to the criticism of ecological reason. Filosofs'ka dumka, № 3, 88 - 108 (2008)

3. S.B. Krymskiy, Morning Reflections. Maysternya Biletskykh, Kyiv (2009)

4. K.M. Maier-Abih, An Uprising for Nature protection. From the Environment to the Common World. Libra, Kyiv ISBN: 966-7035-66 (2004)

5. The idealist. Million bottles per minute: global plastic pollution is "as dangerous as climate change". (In Russian). Retrieved from: https://theidealist.ru/pbottles/

6. S.V. Pustovit, Global Bioethics: the Formation of Theory and Practice (Philosophical Analysis. (In Russian), Arktur, Kyiv (2009)

7. O.P. Skyba, The Danger of the "Bacon" Ideal in Science. (In Ukrainian), Bul. of Nat. Aviat. Univ., 1 (19), 71-74 (2014) http://dx.doi.org/10.18372/2412-2157.19.10274

8. O.P. Skyba, Moral and Ethical Dimension of Ecological Cognition. (In Ukrainian), Bul. of Nat. Aviat. Univ., 2 (18), 117-120 (2013) DOI: 10.18372/2412-2157.18.7489

9. A. Schweitzer, Culture and Ethics. (In Russian) (1973) http://lib.ru/CULTURE/SHWEJCER/kultura.txt

10. V.S. Mokiy, The Limits of Growth. 40 Years Later: Transdisciplinary Rethinking. (in Russian), Universum: Soc. Scie.: elect. scie. j., № 12 (21) (2015)

11. A.S. Nasibulina, The Areas of Interaction of Environmental Ethics and Global Bioethics. (In Russian), Bul. of the BSU, № 14-2 (2014)

12. E. Fromm, Revolution of hope. (In Russian), AST, Moscow (2006)

13. T. Iakovenko, The principle of Responsibility as an Eco-Ethical Imperative for Sustainable Development. (In Ukrainian), Scie. Relig. Soc., № 4 (2010) 